\title{
The case for non-revenue water: Kenya
}

\section{Introduction}

It is clear that cities might eventually run dry if they do not plan their water resources and requirements effectively. A recent case being Cape Town, South Africa. Nairobi City Water and Sewerage Company on the Eastern part of Africa run water and sewer services for Nairobi Kenya and majorly depends on Ndakaini dam as its main water source. The dam's water level has constantly been running low from 2016 to 2017 due to effects of drought. In early 2018, the levels had lowered to alarming rates leading to frequent rationing. Increased population due to rural urban migration has also increased domestic water requirements. Drought and population however may not be the only contributors to frequent water rationing in the cities. Other towns are also experiencing perennial water rationing due to the low efficiency of the water utilities supplying the water to the consumers. This inefficiency consequently reflects in increased non-revenue water (NRW) levels. NRW is known to be a big determinant of the sustainability of any given water utility and hence high NRWs reflect low efficiency and low creditworthiness index. ${ }^{1}$

\section{Non-revenue water in Kenya}

Kenya adopted performance based contracting for water supply and sewerage services through water service providers in 2002 and entered the era of commercialization of these services with the establishment of water service providers. The Kenyan Government through the water act of 2002 and later 2016 established water services regulatory board (WASREB) in order to regulate these water service providers (WSPs). This board established an informational system, which forms a basis of data collection for performance reports that the board annually releases comparing all water companies in Kenya and ranks them based on 67 indicators to form an aggregated performance index. One of the indicators that are in this index is non-revenue water (NRW). Expressed as a percentage, NRW IS the difference between the amount of water produced for distribution and the amount of water billed to customers.

NRW has notably been a major challenge in the Kenyan context. In a third of the water services providers in the country, more than half of the water that was supplied by the WSPs was lost through physical and commercial losses in 2015 . WASREB ${ }^{2}$ estimates that only eight of eighty-six WSPs met the Non-Revenue Water country target of below thirty percent. Comparing year 2014 and 2015, the country experienced an increase in NRW that outweighed the marginal increase in water production in that period implying that despite the fact that water production increased, less water was available for consumption. ${ }^{2}$

NRW levels are alarming in "very large companies" which supply water to more than 35,000 connections. They include Nairobi City, Mombasa, Eldoret, Nakuru, Thika, Kisumu, Nyeri and Kakamega/ Busia water and sewerage companies. These companies had a turnover of USD 109Million in the year 2014-2015 and an average NRW of $40 \%$. This implies that these companies alone lost USD 44million worth of water that year translating to 108 million cubic meters of water lost in leaks, illegal connections, meter reading errors and unbilled consumption! The situation is worse in other smaller companies. A

\author{
Volume 2 Issue 3 - 2018
}

\section{George Kiambuthi Wainaina}

Department of water and environment engineer, Pan African University for Water and Energy Sciences, Algeria

Correspondence: George Kiambuthi Wainaina, Pan African University for Water and Energy Sciences, Algeria, Tel +213 555 290 799, Email gkiambuthi@gmail.com

Received: April 26, 2018 | Published: May 08, 2018

further basic analysis on these individual large companies indicates an increase in NRW as compared with figures for the previous year with the exception of Nairobi city and Nyeri water and sewerage companies. Kakamega/Busia for example increased its NRW from 39 to 53 while Mombasa increased from 48 to $54{ }^{2,3}$ Trends from 2011 indicate that there are some companies like Eldoret and Mombasa, which are consistently performing dismally trend wise in NRW while Kakamega/Busia has consistently maintained high amounts of nonrevenue water going to as high as $67 \%$. While there are signs of improvement in Nairobi City water and Sewerage Company which is one of the biggest, it is evident that more efforts needs to be done to improve its performance on this indicator. Now, approximately 700 litres of water per day per connection is unaccounted for. Due to this, the water company has embarked on an NRW reduction strategy targeting by 2019 to reduce NRW to sixteen percent at an approximate cost of USD 1.6 million. ${ }^{4}$ Considering that the Nairobi City water and Sewerage company lost water valued at around USD 44 million through NRW in year 2013/2014 alone, it must mean that the company needs to review the USD 1.6million investment and increase it to reduce the target time required by if possible to one year or less. This will save them and the country a great deal of revenue. It might not make financial sense launching more water projects in the country and ignoring the large amounts of water lost through NRW. A World Bank report last month indicated that the company's revenue could barely cover its operating costs. ${ }^{1}$ The Figure 1 shows the targets for non-revenue water by Nairobi City Water and Sewerage Company as compared to the actual performance for previous years.

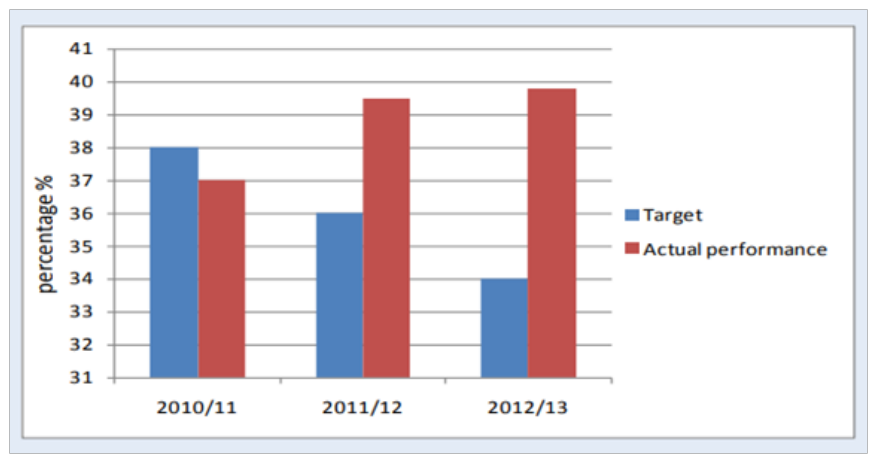

Figure I Targets for non-revenue water by Nairobi City water and sewerage company as compared to the actual performance for previous years. ${ }^{4}$ 


\section{Conclusion and recommendation}

There is a lot that countries like Kenya can borrow from other countries whose water companies and utilities have managed to keep their NRWs low. ONEA water company serves Ouagadougou, Burkina Faso and has maintained an NRW of less than $22 \%$ since $1995,{ }^{5}$ This is a good benchmark. Their revenue covers all operating costs and some capital costs, a result of operational efficiency and a cost recovery tariff. Our neighbors in Uganda implemented customized contracts for managers based on targets as per set indicators where they give a percentage bonus to all managers who achieve their targets, a percentage salary cut to those who do not, and it is working for them. Since the country decided to commercialize water and sewerage services, it will therefore be necessary to view them as businesses and avoid or better, eliminate all forms of losses by improving supply water losses in networks. With the dwindling water resources evidenced by the decline in dam levels at Ndakaini dam, uncertain population influx due to rural urban migration and climate change among other unforeseen challenges, it will be necessary for water companies to embrace technology to handle high NRW levels to compliment other measures in place to ensure achievement of SDG 6. More rapid embrace of geographic information systems to assist in mapping and live pressure monitoring would be a good start. The WSPs should prioritize the implementation of the WASREB 2014 NRW management manual for Kenya as only few of the recommendations have been implemented yet. It is evident that if the water companies in Kenya were private businesses, they would have closed shop. ${ }^{6}$

\section{Acknowledgements}

None.

\section{Conflict of interest}

The author declares there is no conflict of interest.

\section{References}

1. World Bank. Kenya Water Service Provider Creditworthiness Index Report. Washington DC: World Bank. 2015. p. 1-76.

2. WASREB. Performance reports. Nairobi: WASREB. 2016.

3. WASREB. Impact report. Nairobi: WASREB. 2015. p. 1-70.

4. NCWSC. Strategic Plan 2014/15 - 2018/19. Nairobi: NCWSC. 2015. p 40

5. World Bank. Performance of Water Utilities in Africa. Washington DC: World Bank. 2017. p. 1-171.

6. Berg SV, Gakubia RN. PBC for Improving Utilities' Efficiency. In: Gakubia RN, editor. PBC for Improving Utilities' Efficiency. IWA Publishing. 2016. 